\title{
Functionalization of Doped ZnO through Solution Route Synthesis: A study Using Spectroscopy \& Density of States
}

\author{
Poulami Roy $1,+(\mathbb{D})$, Jumana Ishrat ${ }^{1, \uparrow(\mathbb{D})}$, Soumyaditya Sutradhar ${ }^{2 \mathbb{D}}$, Debosreeta Bose ${ }^{1(\mathbb{D})}$, Soumyabrata

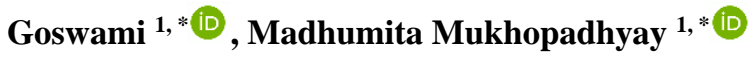 \\ 1 Department of Chemistry, Amity Institute of Applied Sciences (AIAS), Amity University, Kolkata-700156, India; \\ tithipoulami.roy@gmail.com (P.R.); jumanaishrat99@gmail.com (J.I.); dbose@kol.amity.edu (D.B.); \\ sgoswami1@kol.amity.edu (S.G.); mmukhopadhyay@kol.amity.edu (M.M.); \\ 2 Department of Physics, Amity Institute of Applied Sciences (AIAS), Amity University, Kolkata-700156, India; \\ ssutradhar@kol.amity.edu (S.S.); \\ $\dagger \quad$ Both are considered as the first author; \\ * Correspondence: mmukhopadhyay@kol.amity.edu (M.M.); sgoswami1@kol.amity.edu (S.G.); \\ Scopus Author ID 26653695700 (M.M.); 55650987900 (S.G.)
}

Received: 22.11.2020; Revised: 28.12.2020; Accepted: 30.12.2020; Published: 2.01.2021

\begin{abstract}
ZnO}$ is one of the widely studied materials for multidimensional applications, viz. semiconductor material, catalysts, solid-state devices, etc. The primary functionalization is carried out by doping the required element (s) within the $\mathrm{ZnO}$ matrix, which can exist in either zinc blend or the wurtzite form. The present research reports synthesis of $\mathrm{ZnO}$ doped by $\mathrm{Cr}, \mathrm{Y}$, and $\mathrm{Eu}$ at two dopant concentrations. The synthesis technique is optimized using dual fuels during solution auto combustion synthesis. Detailed analysis of X-ray diffraction study reveals a comparative analysis of the peak area and FWHM magnitude. The influence of the doping element on the $\mathrm{ZnO}$ is studied in terms of UV and photoluminescence spectra. The highest bandgap of $3.08 \mathrm{eV}$ is reported with Eu as the dopant within $\mathrm{ZnO}$ compared to $\mathrm{Y}$, which shows lower bandgap energy of $2.44 \mathrm{eV}$. The density of states study of $\mathrm{ZnO}$ is found to be continuous with a significant nodal region within -3.4 to $-2.4 \mathrm{eV}$. However, in the doped systems, irrespective of the dopant, nodal regions are more with specific band regions in the $\mathrm{ZnO}-\mathrm{Y} / \mathrm{ZnO}-\mathrm{Eu}$ system. Irrespective of dopant type, doping within $\mathrm{ZnO}$ significantly influences the states in the conduction band.
\end{abstract}

Keywords: functional material; doped $\mathrm{ZnO}$; photoluminescence spectra; density of states; orbital splitting.

(C) 2020 by the authors. This article is an open-access article distributed under the terms and conditions of the Creative Commons Attribution (CC BY) license (https://creativecommons.org/licenses/by/4.0/).

\section{Introduction}

The basic philosophy behind the advancement of science lies in selecting, choosing, tailoring, and applying appropriate elements within the periodic table, which is the absolute gift from nature to the bio life. Transition elements enable its application in a wide arena like catalysis, bio mimics, energy sector, food industry, etc., owing to the presence of variable oxidation states. Surprisingly, $\mathrm{Zn}$ is an essential trace element for bio life among the Zinc family, which is the primary active metal involved with numerous enzymes like carbonic anhydrase, carboxypeptidase, and alcohol dehydrogenase. However, cadmium and mercury with similar electronic configurations belonging to the same family are toxic in larger proportions for bio life [1]. As per the applicability in bioprocesses, it can be generally stated that involvement of metals within biosystem may either be in the form of a "host-guest" interaction, wherein the metal acted as the guest being circumscribed by a supramolecular 
entity or in the stable oxide form [2]. Among numerous metal oxides, $\mathrm{ZnO}$ is a widely used semiconductor compound. It bears the important traits of low cost, higher chemical stability, mass production, topical drug component, etc. [3]. $\mathrm{ZnO}$ is widely applied as a photocatalyst that undertakes a large cluster of potential; chemical, photochemical, and electrochemical responses [4]. The primary parameters subjected to tailoring for variable application are surface area and surface defects, which govern semiconductor $\mathrm{ZnO}$ 's photocatalytic activity. In addition, doped $\mathrm{ZnO}$ nanoparticles function well as the favorable catalyst for the degradation of organic pollutants due to their high surface activity, morphological features, and feasibility to tailor/induce the defect-driven phenomena [5]. Barua et al. have reported the occurrence of a large band of chemical potential, photochemical, and electrochemical responses on the surface of $\mathrm{ZnO}$ or doped $\mathrm{ZnO}$-based photocatalyst [6]. Doped $\mathrm{ZnO}$ systems are reported to exhibit excellent sensing properties for both oxidizing and reducing gases. The distinctive difference for sensing oxidizing and reducing gas molecules lies in the surface reaction behavior. According to the report of Tee et al., the oxidizing gases get detected by adsorbing at metal oxide (catalyst) surface, whereas the reducing gases like $\mathrm{H}_{2} \mathrm{~S}$ tend to react with chemisorbed oxygen species shown in Eq. 1-3:

$$
\begin{aligned}
& 2 \mathrm{H}_{2} \mathrm{~S}(\mathrm{~g})+3 \mathrm{O}_{2}(\mathrm{ads})^{-} \leftrightarrow 2 \mathrm{H}_{2} \mathrm{O}(\mathrm{g})+2 \mathrm{SO}_{2}(\mathrm{~g})+3 e^{-} \\
& \mathrm{H}_{2}(\mathrm{~g})+\mathrm{O}(\mathrm{ads})^{-} \leftrightarrow \mathrm{H}_{2} \mathrm{O}(\mathrm{g})+e^{-} \\
& \mathrm{CH}_{4}(\mathrm{~g})+4 \mathrm{O}(\mathrm{ads})^{-} \leftrightarrow \mathrm{CO}_{2}+2 \mathrm{H}_{2} \mathrm{O}(\mathrm{g})+2 e^{-}
\end{aligned}
$$

Such sensing mentioned above mechanism required $200-400^{\circ} \mathrm{C}$ operating temperature in case of pristine $\mathrm{ZnO}$. Owing to its low porosity, wide bandgap, and low specific surface area [7-9]. Under this aspect, Habib et al. reported the synthesis of $\mathrm{Cr}$-doped $\mathrm{ZnO}$ by sol-gel technique, which is successful in sending reducing gases with specificity and repeatability at a lower temperature of $50^{\circ} \mathrm{C}$. Debnath et al., on the other hand, reported the hydrothermal synthesized $\mathrm{Cr}$ doped $\mathrm{ZnO}$ wherein the influence of variable doping is studied towards the structural and magnetic response [10]. Increasing doping concentration $\left(\mathrm{Cr}^{3+}\right)$ is found to accelerate oxygen vacancy defects. Again, this oxygen vacancy defect is studied to exhibit a significant role in the enhancement of ferromagnetic ordering in the doped $\mathrm{ZnO}$ nanostructure [11].

Doping of $4 \mathrm{~d}$ transition metal like $\mathrm{Y}$ in $\mathrm{ZnO}$ is also found to significantly influence the "hydrogen energy" by accelerating the Photoelectrochemical (PEC) water splitting with increased photoconversion efficiency (PCE). Commandeur et al. reported Y's doping as dopant within $\mathrm{ZnO}$ for the first time for PEC water splitting [12]. Yttrium-and other doped $\mathrm{ZnO}$ is well known for its conductivity as a n-type semiconductor, leading to applications such as transparent conducting oxide, gas ionization, and humidity sensor [13-19]. On a similar note, doping with lanthanides like $\mathrm{Eu}, \mathrm{Tb}, \mathrm{Yb}$ within $\mathrm{ZnO}$ is applied widely for electronics and optics systems [20]. These ions have narrow emission bands that may also be split or intensified by modifying their chemical environment and micro symmetry [21].

Functionality and applicability of such lanthanide-doped system preferentially depend on the synthetic route of such composite. It has been reported that the solid-state synthesis route tends to segregate the $\mathrm{ZnO}$ and doped metal phase and thereby reduce the endurance of the functional device. Yang et al. reported that $\mathrm{Eu}(\mathrm{III})$ behaves as a shallow electron trap with the $\mathrm{Eu}$ (II) fundamental energy level slightly below the $\mathrm{ZnO}$ conduction band, which can cause the generation of a $\mathrm{ZnO} \rightarrow \mathrm{Eu}(\mathrm{III})$ energy transfer. However, the primary limitation lies in the insertion of lanthanide ions into $\mathrm{ZnO}$, owing to the difference in ionic radii, charge, and coordination number [22, 23]. The reported synthesis route for Eu doped $\mathrm{ZnO}$ involves Pechini 
method [24], hydrothermal synthesis, etc. [25]. Oliveira et al. reported an impregnationdecomposition method to synthesize Eu doped $\mathrm{ZnO}$. to build hierarchically nanostructured multi-layered nanoparticles with alternating undoped $\mathrm{ZnO}$ and $\mathrm{Eu}(\mathrm{III})$-doped $\mathrm{ZnO}$ layers in order to thermally induce $\mathrm{Eu}(\mathrm{III})$ migration into the $\mathrm{ZnO}$ structure. Ashaputre et al. reported the synthesis of $\mathrm{Eu}$ doped $\mathrm{ZnO}$ by chemical means with a variable doping limit [26]. Disorders within the nano $\mathrm{ZnO}$ system are found to get accelerated with an increase in doping \% of Eu. The novelty of such chemically synthesized Eu doped $\mathrm{ZnO}$ is the capability to emit white light within the whole visible range of light. Therefore, it is observed that the doped $\mathrm{ZnO}$ system's functionality depends highly on the synthesis route, which primarily affects the morphology of the matrix. Furthermore, from the literature study, it can be said that to date, numerous studies have been reported based on the application potential of the doped $\mathrm{ZnO}$ system. However, a study on the intrinsic mechanism of defect $\mathrm{ZnO}$ structure needs to be studied in detail.

A novel technique based on solution-phase combustion synthesis is reported to prepare doped $\mathrm{ZnO}$ composite in the present investigation. A detailed study on UV absorption and fluorescence is reported for such doped samples as a doping ratio function. The present investigation's prime novelty lies in the correlation of the pristine $\mathrm{ZnO}$ matrix using a partial density of states concerning the doped counter compositions. A new insight is intended to establish using the theoretical approach for the selective application of these functional materials as a function of dopants for selective applications, as stated above. The three $\mathrm{ZnO}$ system through synthesized using a simple and upscalable solution combustion technique, scientific understanding towards the synthesis using double ligands has been tried to be established not only from the point of various steps involved in the process of ionization and complexation of the various metal ions but also from the point of $\mathrm{pH}$ dependency of the precursor solution and better thermodynamic stability of metal ion-ligand complexes. The study also includes the first principle theoretical analyses of the density of states (DOS) adopting density functional theory (DFT) for the doped ZnO's involved molecular orbitals. This enables to propose the detailed mechanistic ways to evaluate the best suitability of such defect oxides towards such selective application.

\section{Materials and Methods}

The present article involves the synthesis of doped $\mathrm{ZnO}$ composites by $\mathrm{Cr}, \mathrm{Y}$, and $\mathrm{Eu}$. Table 1 illustrates the variability of compositions. All the doped oxide powders were synthesized by simple modified self-sustaining solution combustion technique using $\mathrm{Zn}\left(\mathrm{NO}_{3}\right)_{2}$, $\mathrm{Eu}\left(\mathrm{NO}_{3}\right)_{3} .6 \mathrm{H}_{2} \mathrm{O}, \mathrm{Y}\left(\mathrm{NO}_{3}\right)_{2}, \mathrm{Cr}\left(\mathrm{NO}_{3}\right)_{2} .6 \mathrm{H}_{2} \mathrm{O}$, glycine, and citric acid as starting materials as shown in the preparation scheme in Figure 1.

Table 1. Tabulation of Compositions for doped $\mathrm{ZnO}$ and Sample identifications.

\begin{tabular}{c|c|c|c} 
SI No & Dopant Element & \% of Dopant in ZnO & Sample ID \\
\hline \multirow{2}{*}{1} & $\mathrm{Cr}$ & 0.01 & $\mathrm{ZnO}-\mathrm{Cr}-1$ \\
\cline { 3 - 4 } & & 0.08 & $\mathrm{ZnO}-\mathrm{Cr}-8$ \\
\hline 2 & \multirow{2}{*}{$\mathrm{Y}$} & 0.01 & $\mathrm{ZnO}-\mathrm{Y}-1$ \\
\cline { 3 - 4 } & & 0.08 & $\mathrm{ZnO}-\mathrm{Y}-8$ \\
\hline \multirow{2}{*}{3} & \multirow{2}{*}{$\mathrm{Eu}$} & 0.01 & $\mathrm{ZnO}-\mathrm{Eu}-1$ \\
\cline { 3 - 4 } & & 0.08 & $\mathrm{ZnO}-\mathrm{Eu}-8$
\end{tabular}

The combustion synthesis process is progressed through the involvement of metal ionization steps, followed by the complexation of the metal ions with the ligands. Depending on the $\mathrm{pH}$, the stability of metal-ligand complexes, and the steps of ionization and complexation 
of the metal ions, the fuels have been chosen to serve as a complexing agent. The ratio of the metal nitrate to fuel is fixed at the value at which maximum exothermic reaction occurs during the process of combustion.

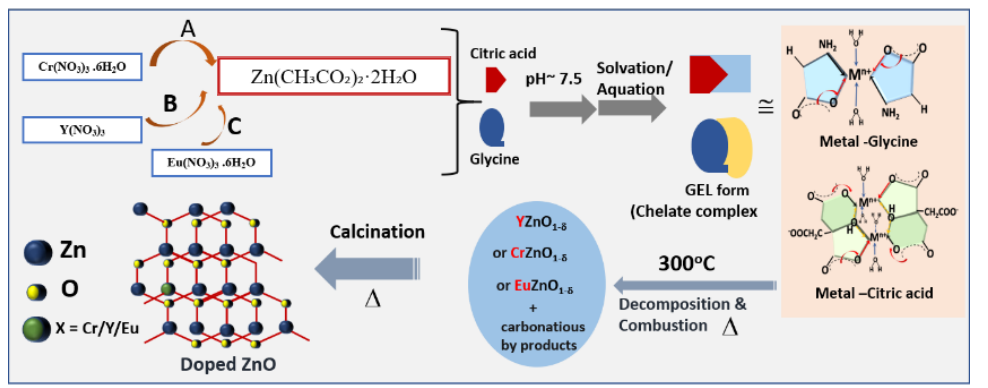

Figure 1. Schematic for preparation of doped $\mathrm{ZnO}$ by solution combustion technique.

In this process, the complexing agents/fuels, alpha-amino acids (glycine), and citric acid have satisfied the metal coordination site by chelating as a bidentate and tetradentate ligand. The overall process consists of an in-between formation of gel followed by the autoignition to form $\mathrm{Zn}$ 's oxidized product along with carbonaceous impurities of the fuel. The final and significant step during the auto combustion process is decomposing the formed chelate complex (s) triggered by external heating at $\sim 300^{\circ} \mathrm{C}$. This is followed by the gel's selfassisted decomposition (complexes) by the added fuel (s). The fuel/ligand promotes the selfdecomposition of the formed complexes. The central metal ion primarily occupies octahedral coordination mode with a specified five/six-membered chelate system. In this connection, during fast in situ decomposition, the fuel/ligand tend to align and reorganize the metal ions in much more stable cubic geometry to enhance (more negative) the crystal field stabilization energy, thereby propagating and terminating the reaction in a spontaneous manner

$$
\left[-\Delta G_{\text {reaction }}=\Delta G_{\text {product }}(\text { hexagonal doped or undoped } \mathrm{ZnO})-\Delta G_{\text {reactant }}(\text { octahedral Metal-Ligand complex })\right] .
$$

The XRD patterns of all the samples were recorded in powder X-ray diffractometer, Model D8, BRUKER AXS, using $\mathrm{Cu} \mathrm{K \alpha}$ radiation $(\lambda=1.5405 \AA)$ in the range of $2 \theta$ from 20 to $80^{\circ}$. The optical absorption (UV-visible) spectrum of the synthesized nanoparticles was taken in 300-700 nm using the Hitachi U-2910 spectrophotometer. The photoluminescence (PL) spectroscopy was carried out using a Hitachi F-4600 fluorescence spectrofluorometer with variable excitation wavelength $\left(\lambda_{\text {ex }}\right)$ dependent on the type of dopant system within the $\mathrm{ZnO}$ matrix. UV sol. 4.2 software was used for the absorption measurement and FL sol. 4.0-4600 software was used for fluorometric measurements. Density functional theory (DFT) is a modeling method used by researchers to determine the electronic structure of many-body systems, such as atoms, molecules, etc. [27]. Using the properties of a many-electron system is often determined by using functionals. In this case, the spatially dependent electron density is computed. DFT is among the leading accepted and adaptable methods available in computational chemistry [28]. We have chosen the pristine and doped $\mathrm{ZnO}$ systems of a very simple, hexagonal symmetry to keep all computational conditions simple and identical. The pristine and the doped crystals were built by GaussView 5.0. The single point energy of the crystal systems (both pristine and doped) was calculated by the Gaussian 09 suite of the quantum chemical program [29]. The corresponding density of states was evaluated by the Gausssum software [30]. 


\section{Results and Discussion}

\subsection{X-ray diffraction analysis.}

The diffraction pattern for $\mathrm{X}$-ray for pristine and $\mathrm{Cr}$-doped $\mathrm{ZnO}$ is shown in Figures 2 and $3 \mathrm{a}$, respectively.
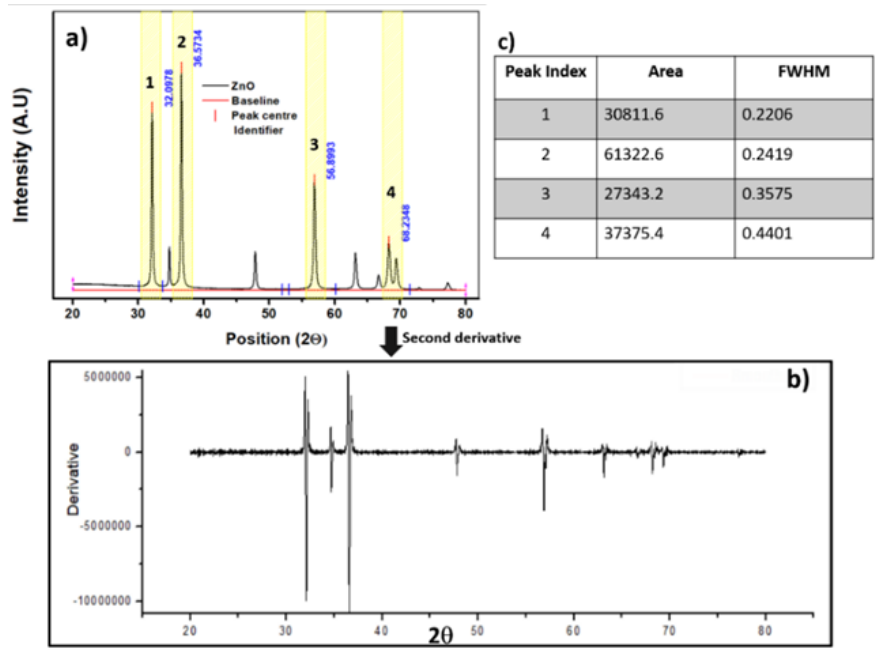

Figure 2. a)XRD pattern of pristine $\mathrm{ZnO}$ with area fitting, b)second derivative plot of a) during fitting, and c) tabulation of fitting parameters.

A detailed study on this specific XRD analysis is reported by Debnath et al. [10], which shows the influence of Cr-doping on the structural and ferromagnetic properties. The reported composite was synthesized using a hydrothermal route. The present investigation's composites are synthesized by solution combustion synthesis followed by thermal calcination to obtain the pure phase material. The XRD shown possesses similar traits, as reported by Debnath et al. [31]. The results depict that the samples are phase pure and are in the single phase of hexagonal wurtzite structure with insignificant impurity level. The literature cited here reveals slight changes in the lattice parameters upon doping, maintaining the intrinsic structure intact. In the present investigation, a peak analyzer using data processing software has been used to study in more detail. The intense and significant peaks are only considered for the fitting purpose, as shown in the peak fitting in Figure 2 a and Figure 3 a.

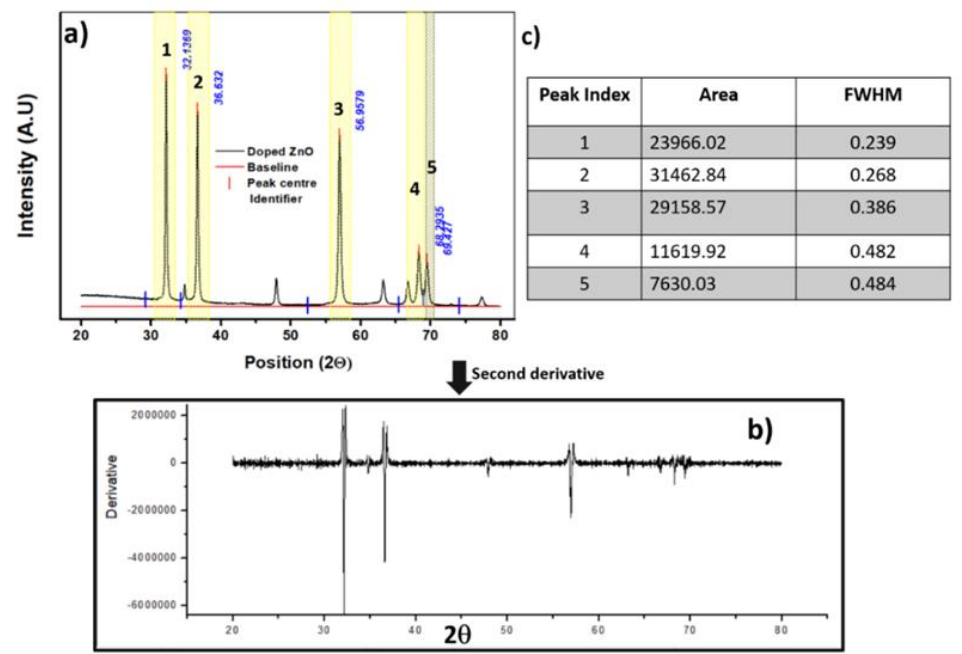

Figure 3. a)XRD pattern of pristine doped $\mathrm{ZnO}(\mathrm{ZnO}-\mathrm{Cr})$ with area fitting, b)second derivative plot of a) during fitting, and c) tabulation of fitting parameters. 
The peaks corresponding to (100), (101), (110), [(112); (201) are considered for both pristine $\mathrm{ZnO}$ and $\mathrm{Cr}$ doped $\mathrm{ZnO}$ system and are marked accordingly. The respective peak positions, peak area, and fullwidth half maxima are given in Figure $2 \mathrm{a}, \mathrm{c}$ and Figure $3 \mathrm{a}, \mathrm{c}$ respectively. The minor details in the lattice parameters are well reflected in these figures. With further increase in doping \%, the corresponding changes in terms of minor peak shifting, area, FWHM, etc., are noted and tabulated in Figures 2 and 3. Figure $2 \mathrm{~b}$ and $3 \mathrm{~b}$ represents the derivative plot for the XRD pattern. This signifies the sustenance of hexagonal wurtzite structure in either a doped or undoped system. The concavity of the XRD pattern is well established. Doping of $\mathrm{Cr}$ is found to influence the (101) plane, which suffers reduced diffraction compared to (100) and (110) planes.

\subsection{UV and photoluminescence study.}

To investigate the optical absorption behavior, room temperature UV-Vis spectra of doped $\mathrm{ZnO}$ samples $(\mathrm{Cr}, \mathrm{Eu}$, and $\mathrm{Y}$ doped) are taken in the range of 300-700 $\mathrm{nm}$ and are shown in Figure 4. The maximum absorption for the $\mathrm{Cr}, \mathrm{Eu}$, and $\mathrm{Y}$ doped $\mathrm{ZnO}$ samples are respectively observed at 376,302 , and $380 \mathrm{~nm}$. The absorbance varies with samples because various factors such as particle size, bandgap, oxygen vacancy, surface roughness, defects in the grain structure, etc., changes the optical absorption behavior. In addition, using absorption spectroscopy, the bandgap energy $\left(\mathrm{E}_{\mathrm{g}}\right)$ of doped $\mathrm{ZnO}$ materials can be estimated since $\mathrm{ZnO}$ is one of the well-known direct bandgap semiconductors. Also, this energy changes with the crystal imperfection developing inside the material induced by the dopant and its concentration. In our case, the optical band gap was calculated using the following relation:

$$
\alpha \mathrm{h} v=\mathrm{A}\left(\mathrm{h} v-\mathrm{Eg}_{\mathrm{g}}\right)^{\mathrm{n}}
$$

where, $\mathrm{h} v$ represents the photon energy, $\mathrm{E}_{\mathrm{g}}$ stands for optical band gap energy, $\alpha$ is the absorption coefficient, and $\mathrm{A}$ is a constant. From the plots of $\mathrm{h} v\left(\right.$ Energy, E) versus $(\alpha \mathrm{h} v)^{2}$ (Figure 5), the band gaps of $\mathrm{Cr}$ doped $\mathrm{ZnO}$ is found to be $2.92 \mathrm{eV}$, that of $\mathrm{Eu}$ doped $\mathrm{ZnO}$ is $3.08 \mathrm{eV}$, and finally, that of $\mathrm{Y}$ doped $\mathrm{ZnO}$ is $2.44 \mathrm{eV}$.

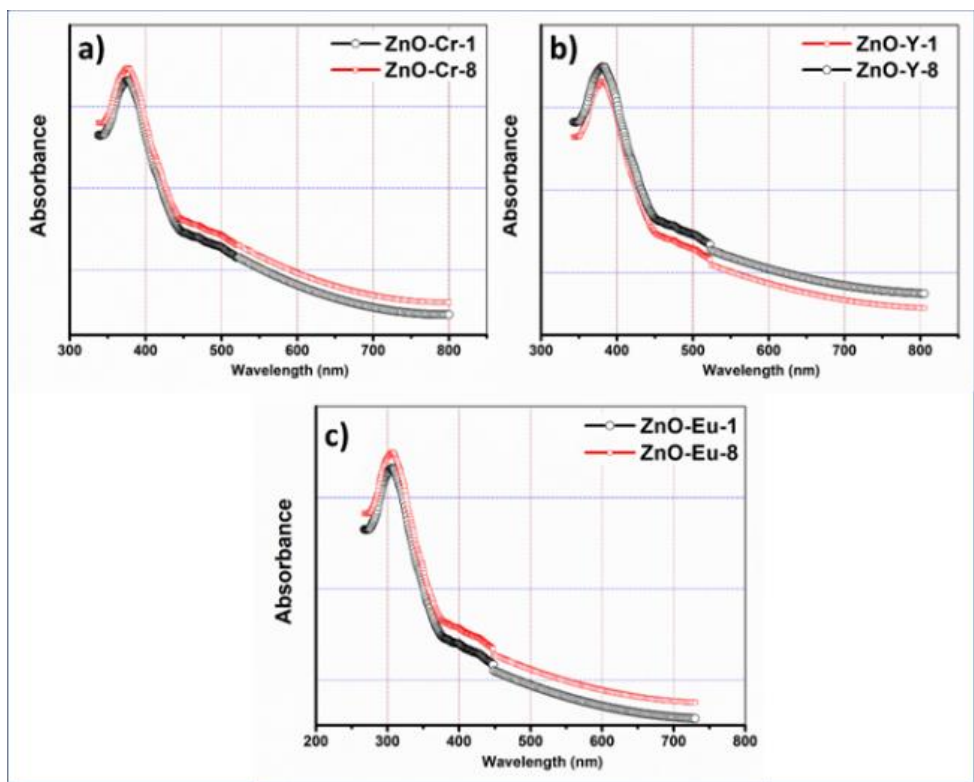

Figure 4. UV absorption spectra for: a)Cr doped $\mathrm{ZnO}$ ( $\mathrm{ZnO}-\mathrm{Cr}$ system), b) $\mathrm{Y}$ doped $\mathrm{ZnO}$ (ZnO-Y system), and c) Eu doped $\mathrm{ZnO}$ ( $\mathrm{ZnO}-\mathrm{Eu}$ system). 
Room temperature photoluminescence (PL) measurements of all the doped $\mathrm{ZnO}$ nanomaterials ( $\mathrm{Cr}, \mathrm{Eu}$, and $\mathrm{Y}$ doped) have been performed. The PL spectrum is shown in Figure 6. The PL study of $\mathrm{Cr}, \mathrm{Eu}$, and $\mathrm{Y}$ doped $\mathrm{ZnO}$ nanoparticles is carried out respectively with excitation wavelengths of 345, 292, and $380 \mathrm{~nm}$. The PL spectrum of $\mathrm{Cr}$ doped $\mathrm{ZnO}$ shows a prominent emission at $392 \mathrm{~nm}$, and $\mathrm{Y}$ doped $\mathrm{ZnO}$ depicted emissions at 410 and $440 \mathrm{~nm}$. These emissions are in the violet and blue region of the visible spectrum and arise due to the electronic transition from the interstitial zinc level ( $\mathrm{IZn}_{\mathrm{Zn}}$ ) to the valence band's top. For Eu doped ZnO, UV emission at $376 \mathrm{~nm}$ was observed. This emission peak appeared due to the free exciton recombination governed by the exciton-exciton collision process and are assigned to a nearband-edge (NBE) emission band. In the present context, experiments are carried out with two doping \% of each $\mathrm{Cr}, \mathrm{Y}$, and Eu respectively. Figure 5 and 6 shows the plots for both UV and PL spectra for all the compositions. It could be observed that the higher concentration of doping does not influence the spectral nature. However, the resultant intensity feebly increases for UV plots and slightly for the PL study, respectively.
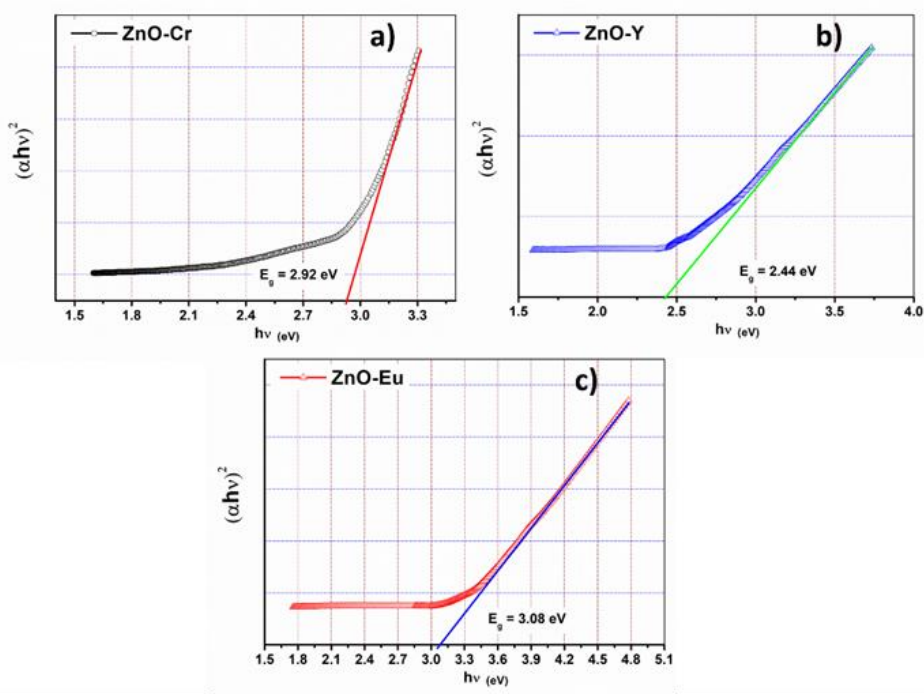

Figure 5. UV absorption spectra for: a)Cr doped $\mathrm{ZnO}$ (ZnO-Cr system), b) $\mathrm{Y}$ doped $\mathrm{ZnO}$ (ZnO-Y system), and c) $\mathrm{Eu}$ doped $\mathrm{ZnO}$ (ZnO-Eu system). UV is given for two doped compositions for all dopants
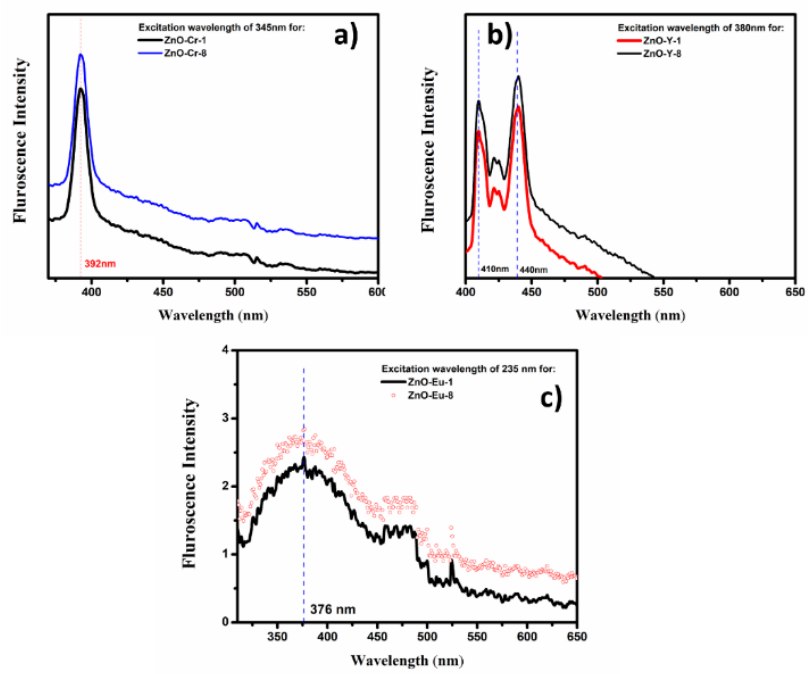

Figure 6. Photoluminiscence specra for: a)Cr doped $\mathrm{ZnO}$ ( $\mathrm{ZnO}-\mathrm{Cr}$ system), b) $\mathrm{Y}$ doped $\mathrm{ZnO}$ ( $\mathrm{ZnO}-\mathrm{Y}$ system) and c) Eu doped $\mathrm{ZnO}$ (ZnO-Eu system). PL is given for two doped compositions for all dopants 3.3. Study on the functionality of doped $\mathrm{ZnO}$ from a partial density of states. 
Doping of actinide series, Eu is found to result in a maximum bandgap of $3.08 \mathrm{eV}$ compared to least bandgap caused by transition elements. The spectra show a broad peak stretching from $370 \mathrm{~nm}$ (ZnO band-to-band transition) to $620 \mathrm{~nm}$ (Eu ${ }^{3+}$ transitions), which covers the visible light regime's wavelength. It is obvious that an energy transfer from the $\mathrm{ZnO}$ host to $\mathrm{Eu}^{3+}$ is the dominant process responsible for broad luminescence. The observed higher intensity in the case of higher doping concentration suggests that there is more energy transfer from host $\mathrm{ZnO}$ nanoparticles to $\mathrm{Eu}^{3+}$ ions.

Figure 7 shows the density of states plot as a function of the spin state for both pristine $\mathrm{ZnO}$ and doped $\mathrm{ZnO}$ system. Owing to $\mathrm{ZnO}$ 's significant semiconducting regions, both conduction and valence band regime coexists in all DOS plots. The nodal regions within the doped compounds are pointed using an arrow in Figure 7b-d, respectively. The DOS of $\mathrm{ZnO}$ is found to be continuous, with a significant nodal region within -3.4 to $-2.4 \mathrm{eV}$.
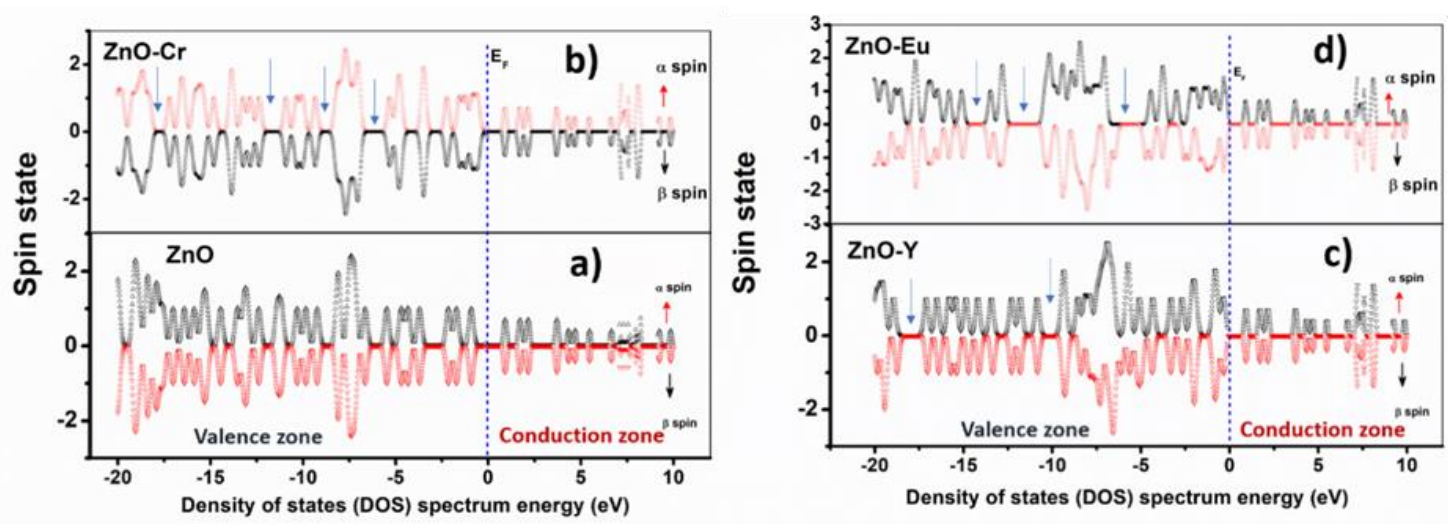

Figure 7. Density of states spectrum energy as a function of electronic spin state for a)ZnO; b) $\mathrm{Cr}$ doped $\mathrm{ZnO}$ ( $\mathrm{ZnO}-\mathrm{Cr}$ system), c) Y doped $\mathrm{ZnO}$ ( $\mathrm{ZnO}-\mathrm{Y}$ system), and d) Eu doped $\mathrm{ZnO}$ (ZnO-Eu system).

However, in the doped systems, irrespective of the dopant, nodal regions are more with more specific band regions in the $\mathrm{ZnO}-\mathrm{Y} / \mathrm{ZnO}-\mathrm{Eu}$ system. The majority spin channel contains a flat region of majority spin states in the middle energy range, thereby spanning the energy states. These states are possibly hybrid TM3d (TM: transition metal) and O2p states. The atomic states' interaction with the valence band (VB) or conduction band (CB) would form bonding and antibonding states, as shown in Figures 8 and 9, respectively.

Except for pristine $\mathrm{ZnO}$, it is shown that the valence band of the doped system is divided (w.r.t nodal plane) into two regions for $\mathrm{ZnO}-\mathrm{Cr}$ and $\mathrm{ZnO}-\mathrm{Eu}$. The lower valence within -18 to $11.5 \mathrm{eV}$ and the upper valence band within -5.5 to $0 \mathrm{eV}$. The upper valence is mainly contributed by the $2 \mathrm{p}$ states of $\mathrm{O}$, and the lower valence band is chiefly contributed by the $3 \mathrm{~d}$ states of $\mathrm{Zn}$, which is segregated by the doped species. Such discrimination of zones within the valence band is absent in the pristine $\mathrm{ZnO}$ system. For $\mathrm{ZnO}-\mathrm{Y}$, the nodal planes are limited to $-18 \mathrm{eV}$ and $-11 \mathrm{eV}$ in the valence zone with a very low stretch. Moreover, the $3 \mathrm{~d}$ states of $\mathrm{Zn}$ and $2 p$ states of oxygen have a role in orbital hybridization, and the electron states have a certain overlap between each other, indicating $\mathrm{ZnO}$ has a covalent bond and a strong role of an ionic bond. Such overlapping or coherency is more within $\mathrm{Y}$-doped $\mathrm{ZnO}$, as can be visible from Figure $7 \mathrm{~d}$. The conduction band is primarily contributed by the $\mathrm{Zn} 4 \mathrm{~s}$ states and the $\mathrm{O}-2 \mathrm{p}$ states. According to Hachimi et al. [32], for the Eu ion, $4 \mathrm{f}$ orbital tends to split into three parts due to the tetrahedral field. After binding, it usually achieves its stable 3+ oxidation state. It can also be noted from Figure 7 that doping of elements tends to influence the conduction band of the DOS spectrum wherein orbital interaction generates in the doped matrix. In contrast, the 
pristine system's DOS exhibits much less orbital interaction and charge transfer compared to the doped counterparts. The Fermi energy regime is also highlighted within the DOS at the zero-energy point.

The study on the density of states as a function of electronic spin is derived from orbital splitting. It is known that combustion synthesis involves the formation of an initial octahedral complex during aquation, which may finally lead to a lower or higher in symmetry towards cubic, tetrahedral, octahedral, or other geometries (during anation). Selection of final geometry involves optimization of crystal filed/ligand filed stabilization energy, which includes loss of degeneracy of the involved orbitals, specifically d- or f orbitals. Figures 8 and 9 show the orbital splitting pattern with respect to HOMO/LUMO molecular orbitals as a function of the $\mathrm{ZnO}$ system's associated energies. It is mentioned in the mechanistic approach in Figure 1 that combustion synthesis involves the formation of an initial octahedral complex during aquation, which may finally lead to a lower or higher symmetry towards cubic, tetrahedral, octahedral, or other geometries (during anation). Selection of final geometry involves optimization of crystal filed/ligand filed stabilization energy, which includes loss of degeneracy of the involved orbitals, specifically d- or f orbitals. As expected, irrespective of the composition, participating metal orbitals' population density is high in the highest occupied molecular orbitals. During computation of DOS, the doped systems are iterated and found to be devoid of any symmetry operation owing to which the splitted orbital degeneracy are all denoted to be of even singular symmetry (denoted by A).

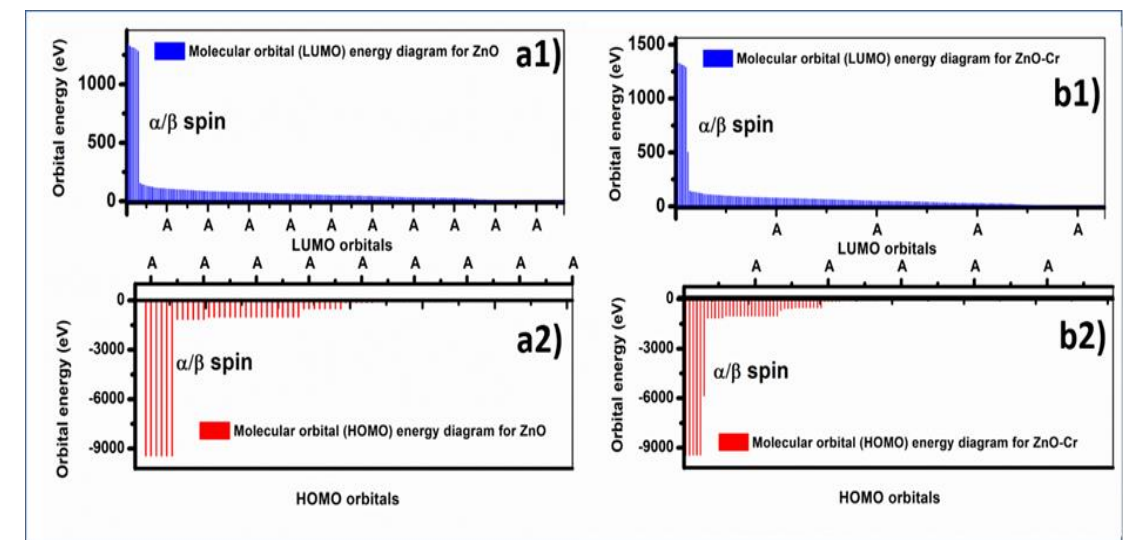

Figure 8. Orbital splitting as a function of energy for HOMO and LUMO sets for a1); a2)ZnO and b1); b2) $\mathrm{Cr}$ doped $\mathrm{ZnO}(\mathrm{ZnO}-\mathrm{Cr}$ system).
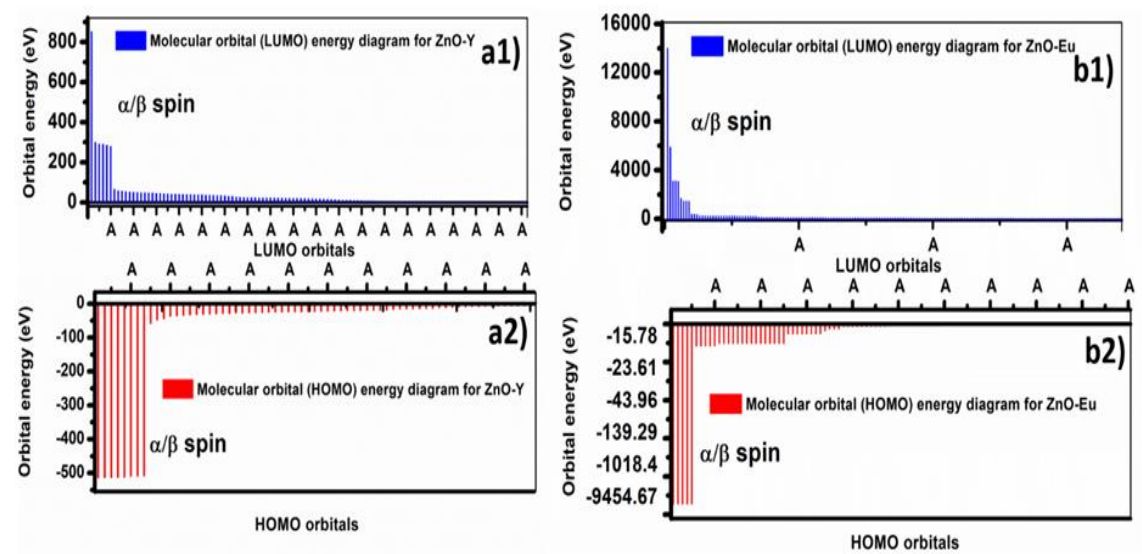

Figure 9. Orbital splitting as a function of energy for HOMO and LUMO sets for a1); a2) Y doped $\mathrm{ZnO}$ ( $\mathrm{ZnO}$ Y) and b1); b2) Eu doped $\mathrm{ZnO}$ (ZnO-Eu system). 
The extent of stabilization of the doped $\mathrm{ZnO}$ system can be accounted for by the orbital energy (marked by attractive negative energy in the HOMO orbital graph). It could be noted that the extent of attractive energy in HOMO is lower in the ZnO-Y system compared to either $\mathrm{Cr}$ or Eu doped $\mathrm{ZnO}$. The $\mathrm{Y}$ doping system exhibits a direct bandgap like pure $\mathrm{ZnO}$. Owing to such fact, they tend to enhance the system's optical and electrical properties, thereby acting as an active participant in Photochemical water-splitting reaction. On the other hand, comparatively more stabilized HOMO of $\mathrm{ZnO}-\mathrm{Eu}$ tends to show shallow electron trapping, which can cause the generation of a $\mathrm{ZnO} \rightarrow \mathrm{Eu}(\mathrm{III})$ energy transfer [33, 34]. Therefore, it could be stated that the study of PDOS spectra can act as a guide/ tracer to tailor the mode of functionality for a selective doped system.

\section{Conclusions}

In a nutshell, the present investigation reports pristine $\mathrm{ZnO}$ material's functionalization by doping with $\mathrm{Cr}, \mathrm{Y}$, and $\mathrm{Eu}$, respectively. It is apprehended from literature study that the structure-property correlation for a functional system is highly dependent on the processing technique, which can tailor the morphology of the composite.

The present research article report synthesis of $\mathrm{ZnO}$ doped by $\mathrm{Cr}, \mathrm{Y}$, and $\mathrm{Eu}$ at two dopant concentrations. The authors' have employed solution/ auto combustion synthesis to prepare such composites. The synthesis technique is optimized using dual fuels or ligand during solution auto combustion synthesis like citric and glycine. This enables an initial complexation of the central metal ion (with doped elements) followed by its optimized decomposition. The synthesized doped matrix is characterized using X-ray diffraction analyses and spectroscopic tools primarily. XRD study proves the samples' phase purity and reveals a comparative analysis of the peak area and FWHM magnitude. The influence of the doping element on the $\mathrm{ZnO}$ is studied in terms of UV and photoluminescence spectra. Irrespective of doping \%, the UV plots are identical concerning the dopant element but exhibit peak shifting with a dopant element variation. The maximum absorption for the $\mathrm{Cr}$, $\mathrm{Eu}$, and $\mathrm{Y}$ doped $\mathrm{ZnO}$ samples are respectively observed at 376,302 , and $380 \mathrm{~nm}$. The absorbance varies with samples because various factors such as particle size, bandgap, oxygen vacancy, surface roughness, defects in the grain structure, etc., changes the optical absorption behavior. The highest bandgap of $3.08 \mathrm{eV}$ is reported with $\mathrm{Eu}$ as the dopant within $\mathrm{ZnO}$ in comparison to $\mathrm{Y}$, which shows lower bandgap energy of $2.44 \mathrm{eV}$. These bandgap energies are calculated from Tauc plots using UV spectral data. In addition to the mentioned experimental studies, theoretical analyses are carried out based on states' first principle density. Such study is primarily based on the geometry optimization of the pristine/ doped $\mathrm{ZnO}$ system. The DOS plots clearly manifest the presence of both valence and conduction bands in the doped and pristine $\mathrm{ZnO}$. The density of states study of $\mathrm{ZnO}$ is found to be continuous with a significant nodal region within -3.4 to $-2.4 \mathrm{eV}$. However, in the doped systems, irrespective of the dopant, nodal regions are more with specific band regions in the $\mathrm{ZnO}-\mathrm{Y} / \mathrm{ZnO}-\mathrm{Eu}$ system. Irrespective of dopant type, doping within $\mathrm{ZnO}$ significantly influences the states in the conduction band. Such theoretical study enables the analyses of binding within the system using the molecular orbital concept. It can act as a calibration tool to optimize the associated properties, further validated using experimental tools. 


\title{
Funding
}

This research was partly funded by Amity University, Kolkata, as a part of Degree course credit courses based on the research aspect.

\section{Acknowledgments}

\author{
Financial and infrastructural support from Amity University Kolkata is gratefully \\ acknowledged.
}

\section{Conflicts of Interest}

The authors declare no conflict of interest.

\section{References}

1. Genchi, G.; Sinicropi, M.S.; Lauria G.; Carocci, A.; Catalano, A. The Effects of Cadmium Toxicity. Int J Environ Res Public Health 2020, 17, 1-24, https://doi.org/10.3390/ijerph17113782.

2. Ma, X.; Zhao, A. Biomedical Applications of Supramolecular Systems Based on Host-Guest Interactions. Chemical Reviews 2015, 115, 7794-7839, https://doi.org/10.1021/cr500392w.

3. Carofiglio, M.; Barui, Sugata.; Cauda, V.; Laurenti, Marco. Doped Zinc Oxide Nanoparticles: Synthesis, Characterization and Potential Use in Nanomedicine. Appplied Sciences 2020, 10, 5194-1-43, https://doi.org/10.3390/app10155194.

4. Xiaoqing, Chen.; Zhansheng, W.; Dandan, L.; Zhenzhen, Gao. Preparation of ZnO Photocatalyst for the Efficient and Rapid Photocatalytic Degradation of Azo Dyes. Nanoscale Research Letters. 2017, 12, 143-110, https://doi.org/10.1186/s11671-017-1904-4.

5. Mirzaeifard, Z.; Shariatinia, Z.; Jourshabani, M.; Darvishi, S.M.R. ZnO Photocatalyst Revisited: Effective Photocatalytic Degradation of Emerging Contaminants Using S-Doped ZnO Nanoparticles under Visible Light Radiation. Ind. Eng. Chem. Res. 2020, 59, 15894-15911, https://doi.org/10.1021/acs.iecr.0c03192.

6. Baruah, S.; Pal ,K.. Samir.; Dutta, J. Nanostructured zincoxide for water treatment, Nanoscale Nanotechnology- Asia 2012, 2, 90-102, https://doi.org/10.2174/2210681211202020090.

7. Husen, A. Gold nanoparticles from plant system: Synthesis,characterization and their application.Nanoscience and plant soil system 2017, 48, 455-479, https://doi.org/10.1007/978-3-319-468358_17.

8. Chaudhury, Q.; Scotter, M.; Blackburn, J.; Ross, B.; Boxall, A.; Castle, L.; Aitken, R.; Watkins, R. Applications and implications of nanotechnologies for the food sector. Food Additives and Conaminants: PartAChemistry 2008, 25, 241-258, https://doi.org/10.1080/02652030701744538.

9. Siddiqi, K.S.; Rahman, A.; Tajuddin.; Husen, A. Properties of zinc oxide nanoparticles and their activity against microbes. Nanoscale Research Letters 2018, 13, https://doi.org/10.1186/s11671-018-2532-3.

10. Debnath ,T.; Bandyopadhyay, A.; Chakraborty, T.; Das, S.; Sutradhar, S. Influence of different Cr concentrations on the structural and ferromagnetic properties of $\mathrm{ZnO}$ nanomaterials prepared by the hydrothermal synthesis route. Materials Research Bulletin 2019, 118, https://doi.org/10.1016/j.materresbull.2019.05.005.

11. Nasir, A.; Singh, B.; Khan, Z. A.; A. R. Vijaya.; Tarafdar, K.; Gosh, S. Origin of ferromagnetism in Cudoped ZnO. Scientic Reorts. 2019, 9, 2461-1-7, https://doi.org/10.1038/s41598-019-39660-x.

12. Commandeur, D.; Brown, G.; McNulty, P.; Dadswell, C.; Spencer, J.; Chen, Q. Yttrium-Doped ZnO Nanorod Arrays for Increased Charge Mobility and Carrier Density for Enhanced Solar Water Splitting. J.Phys, Chem. 2019, 30, 18187-18197, https://doi.org/10.1021/acs.jpcc.9b03609.

13. Wang, J.; Fan, S.; Xia, Y.; Yang, C.; Komarneni S. Room-temperature gas sensors based on ZnO nanorod/Au hybrids: Visible-light-modulated dual selectivity to $\mathrm{NO}_{2}$ and $\mathrm{NH}_{3}$. Journal of Hazardous Materials 2020, 381, 120919-120920, https://doi.org/10.1016/j.jhazmat.2019.120919.

14. Youvanidha, A.; Vidhya, B.; Nelson, P.I.; Kannan, R.R.; Suresh Babu, S.K. Investigation on the Structural, Optical and Electrical Properties of ZnO-Y2O3 (YZO) Thin Films Prepared By PLD for TCO Layer Applications. AIP Conf. Proc. 2019, 2166, https://doi.org/10.1063/1.5131610.

15. Sarf, F.; Karaduman, Er I.; Yarkar, E.; Acar, S. The role of rare-earth metal (Y, Ru and Cs)-doped ZnO thin films in $\mathrm{NH}_{3}$ gas sensing performances at room temperature. Journal of Materials Science: Materials in Electronics 2020, 31, 10084-10095, https://doi.org/10.1007/s10854-020-03554-w.

16. Bhati, V.S.; Hojamberdiev, M.; Kuma, M. Enhanced sensing performance of $\mathrm{ZnO}$ nanostructures-based gas sensors:A review. Energy Reports 2020, 6, 46-62, https://doi.org/10.1016/j.egyr.2019.08.070.

17. Bazta, O.; Urbieta, A.; Piqueras, J.; Fernández, P.; Addou, M.; Calvino, J.J.; Hungría, A.B. Influence of yttrium doping on the structural, morphological and optical properties of nanostructured $\mathrm{ZnO}$ thin films 
grown by spray pyrolysis. Ceramic International 2019, 45, 6842-6858, https://doi.org/10.1016/j.ceramint.2018.12.178.

18. Zhang, C.; Luo, Y., Xu, J.; Debliquy, M. Room temperature conductive type metal oxide semiconductor gas sensors for $\mathrm{NO}_{2}$ detection. Sensor and Actuators A:Actual. 2019, 289, 118-133, https://doi.org/10.1016/j.sna.2019.02.027.

19. Sirel khatim, A.; Azman, S.M.; Haida, S.N.; Kaus, M.; Chuo, L.; Khadijah, A.S.; Bakhori, S.K.; Hasan, H.; Mohamad, D. Review on zinc oxide nanoparticles: Antibacterial activity and toxicity mechanism. NanoMicro Lett. 2015, 7, 219-242, https://doi.org/10.1007/s40820-015-0040-x.

20. Leela, B.H.P.; Rajendran, D.N. Effect of lanthanide ion co-doping on the luminescence in the cerium-doped zinc oxide-phosphor system. Spectrscopic Letters. 2019, 52, 431-440, https://doi.org/10.1080/00387010.2019.1659824.

21. Kubota, S.; Izumi, M.; Yamane, H.; Shimada, M. Luminescence of $\mathrm{Eu}^{3+}, \mathrm{Tb}^{3+}$ and $\mathrm{Tm}^{3+}$ in $\mathrm{SrLaGa}_{3} \mathrm{O}_{7}$. Journal of Alloys and Compounds 1999, 283, 95-101, https://doi.org/10.1016/S0925-8388(98)00866-4.

22. Jiang, N.; Ye, S.; Qiu, J. Electron energy-loss spectroscopy study of Yb doped ZnO. J. Appl. Phys. 2010, 108, 1-4, https://doi.org/10.1063/1.3493260.

23. Shannon, R. D.; Prewitt, C. T. Effective ionic radii in oxides and fluorides. Acta Cryst. 1969, B25, 925-946, https://doi.org/10.1107/S0567740869003220.

24. Lima, S.A.; Sigoli, M.; Davolos, F.A.; Davalos, M.R. Pechini's solution as precursor for Eu(III)-containing ZnO films. J. Solid State Chem. 2003, 171, 287-290, https://doi.org/10.1016/S0022-4596(02)00178-0.

25. Lopez, J.L.C.; Rangel, R.; Cedeno, V.J.; Alvarado Gil, J.J.; Quintana, P.; Contreras, O.; Espino, J. Controlling the aspect ratio of $\mathrm{Zn}_{(1-x)} \mathrm{Eu}_{(x)} \mathrm{O}$ nanostructures obtained by a statistical experimental design involving atomic layer deposition and microwave-assisted hydrothermal methods. Applied Physics A. 2019, 125, https://doi.org/10.1007/s00339-018-2362-2.

26. Ashtaputre, S.S.; Nojima, A.; Marathe, S.K.; Matsumura, D.; Ohta, T.; Tiwari, R.; Dey, G.K.; Kulkarni, S.K. Investigations of white light emitting europium doped zinc oxide nanoparticles. J. Phys. D: Appl. Phys. 2008, 41, https://doi.org/10.1088/0022-3727/41/1/015301.

27. Bagayoko, D. Understanding density functional theory (DFT) and completing it in practice. AIP Advances 2014, 4, 1-12, https://doi.org/10.1063/1.4903408.

28. Gross, E.K.U.; Driezler, R.M. Density Functional Theory. NATO ASI Series 1993, 337, 16-27, https://doi.org/10.1007/978-1-4757-9975-0.

29. Frisch, M.J.; Trucks, G.W.; Schlegel, H.B.; Scuseria, G.E.; Robb, M.A.; Cheeseman, J.R.; Scalmani, G.; Barone, V.; Mennucci, B.; Petersson, G.A.; Nakatsuji, H.; Caricato, M.; Li, X.; Hratchian, H.P.; Izmaylov, A.F.; Bloino, J.; Zheng, G.; Sonnenberg, J.L.; Hada, M.; Ehara, M.; Toyota, K.; Fukuda, R.; Hasegawa, J.; Ishida, M.; Nakajima, T.; Honda, Y.; Kitao, O.; Nakai, H.; Vreven, T.; Montgomery, J.A.; Peralta, Jr. J.A.; Ogliaro, F.; Bearpark, M.; Heyd, J.J.; Brothers, E.; Kudin, K.N.; Staroverov, V.N.; Kobayashi, R.; Normand, J.; Raghavachari, K.; Rendell, A.;. Burant, J.C.; Iyengar, S.S.; Tomasi, J.; Cossi, M.; Rega, N.; Millam, J.M.; Klene, M.; Knox, J.E.; Cross, J.B.; Bakken, V.; Adamo, C.; Jaramillo, J.; Gomperts, R.; Stratmann, R.E.; Yazyev, O.; Austin, A.J.; Cammi, R.; Pomelli,R.; Ochterski, J.W.; Martin, R.L.; Morokuma, K.; Zakrzewski, V.G.; Voth, G.A.; Salvador, P.; Dannenberg, J.J.; Dapprich, S.; Daniels, A.D.; Farkas, O.; Foresman, J.B.; Ortiz, J.V.; Cioslowski, J.; Fox, D.J. Gaussian 09 Gaussian, Inc., Wallingford CT, 2009.

30. O'Boyle, N.M.; Tenderholt, A.L.; Langner, K.M. Cclib: A library for package-independent computational chemistry algorithms. J. Comp. Chem. 2008, 29, 839-845.

31. Debnath, T.; Bandyopadhyay, A.; Chakraborty, T.; Das, S.; Sutradhar, S. Influence of different $\mathrm{Cr}$ concentrations on the structural and ferromagnetic properties of $\mathrm{ZnO}$ nanomaterials prepared by the hydrothermal synthesis route, Materials Research Bulletin. 2019, 118, 1-12, https://doi.org/10.1016/j.materresbull.2019.05.005.

32. Hachimi, A.G.E.; Zaari, H.; Hamedoun, M.; Benyoussef, H.; Kenz, A.E.; Mounkachi, O. Experimental and theoretical investigation of $\mathrm{Nd}$ doped ZnO. Journal of Magnetism and Magnetic Materials. 2017, 444, 416420, https://doi.org/10.1016/j.jmmm.2017.08.058.

33. Oliveira, C.S.; Bettini.; Sigoli, F.A.; Mazali, I.O. Europium(III)-Doped ZnO Obtained by a Hierarchically Nanostructured Multilayer Growth Strategy. Cryst. Growth Des. 2015, 15, 5246-5253, https://doi.org/10.1021/acs.cgd.5b00712.

34. Singh, A.; Arya, P.; Choudhary, D.; Kumar, S.; Srivastava, A.K.; Singh, I.B. Cost-effective ZnO-Eu ${ }^{3+}$ films with efficient energy transfer between host and dopant. SN Appl. Sci. 2020, 2, https://doi.org/10.1007/s42452-020-2670-y. 